\title{
fiterarifde \#eridate.
}

No. 3 .

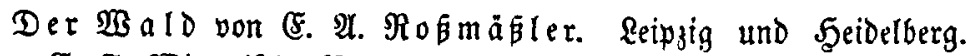

6. F. Binter'fibe $\mathfrak{B}$ erlagebandlung. 2. und 3. Rieferung.

Bix haben auf Eeite 156 u. f. Dez Jahrgangz 1861 Diefer 3eitjđurift über Dag obige Wert beriđtet, und e\& unjern Refern beftens empfoblen. Die mit 4 gleid) vortreffliden Bildern (Reg= föhre, (Eide, Bergahorn uno $\mathfrak{i} i e f e r)$ aug̉gejtatteten neuen Rieferungen

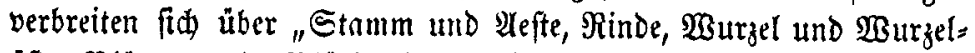
åfte, Blätter und $\mathfrak{B l u ̈ t h e n " ~ u n d ~ f d d l i e f e n ~ f o ~ d i e ~ i m ~ 1 . ~ S e e f t ~ b e - ~}$

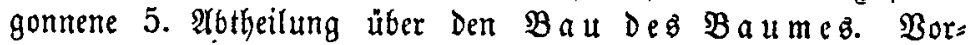

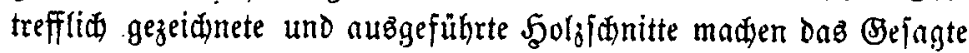
bis auf's Meuperfite binaus flar und für jeden Bebildeten ver= ftändliđi.

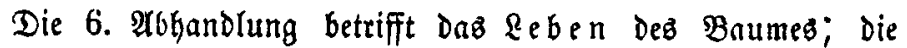
7. Die $\mathfrak{A} \mathfrak{r}$ iteftur Der $\mathfrak{B} a$ I

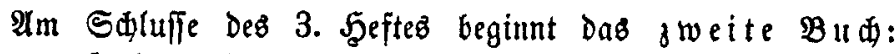

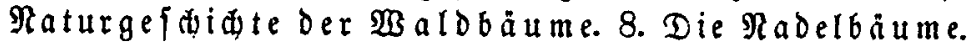

Reidhaltige Belehrung in anfpredjendfer form ift nut in Diefen Rieferungen zu finden, auf eine nälere Erörterung unz ein= zulaffen balten wir nidjt melyr fử nötfitg, Da Das vortrefflitye Berf bereitż fĭh altentbalben Babn gebrodjen zu haben fajeint, wenigftens baben wir es bereits in Sänden gefeben, in Denent wir ez nie vermutheten, und bie vollife Zufriedenheit bon foldjen Eejern ausfpredien hören, welde mit Dem Gorftwefen in feiner Berüfrung flehen. Utm fo mehr wiro man von jedem forfmann verlangen Dürfen, Daß famfeit wiome.

Beruntwortlitier Rebacteur: . Dengler, Bez̧irfbföfter unb gebrer an ser forftiduls in Garlbruge. - Drua uno Berlag yon G. Edoweijerbart in Stuttgart. 